\title{
Comparison of the early cardiac electromechanical remodeling following transcatheter and surgical secundum atrial septal defect closure in adults
}

Amr Mansour ${ }^{1}$ (D), Noha M. Gamal2 ${ }^{2 *}$ M. Alaa Nady ${ }^{3}$, Salwa R. Demitry², H. Shams-Eddin ${ }^{2}$ and Khaled M. El-maghraby ${ }^{2}$

\begin{abstract}
Background: Secundum atrial septal defect (ASD) closure leads to electrical and mechanical remodeling that occurs early after shunt disappearance. The relationship between electromechanical remodeling using electrocardiogram (ECG) and cardiac magnetic resonance (CMR) after percutaneous and surgical closure has not yet been recorded in prospective studies.

Objective: We thought to study right atrium (RA) and right ventricle (RV) changes by CMR 3 months after transcatheter and surgical closure and their comparison with electrical remodeling by ECG.

Results: We prospectively evaluated 30 consecutive adult patients with isolated secundum ASD who were referred for (transcatheter and surgical) ASD closure.

There was significant reduction in all of the electrical parameters within the same group as compared to the baseline values, except $\mathrm{P}$ wave dispersion (Pd). ( $\mathrm{P}$ max was $97.33 \pm 16.67$ (pre closure) to $76 \pm 15.49$ (post closure) in the device group and $97.33 \pm 12.79$ (preclosure) to $73.33 \pm 16.32$ (post closure) in the surgical group, QRS complex was $104 \pm 18.82$ (preclosure) to $80 \pm 18.51$ (post closure) in the device group and $106.67 \pm 14.47$ (preclosure) to $86.67 \pm 17.99$ (post closure) in the surgical group. QTc maximum was $478.53 \pm 36.79$ (preclosure) to $412.53 \pm 38.03$ (post closure) in the device group and $470.53 \pm 65.70$ (preclosure) to $405.93 \pm 63.08$ (post closure) in the surgical group, and QTc dispersion was $70.33 \pm 24.04$ (preclosure) to $60.26 \pm 28.56$ (post closure) in the device group and $80.73 \pm 30.38$ (preclosure) to $60.27 \pm 28.57$ (post closure) in the surgical group).There was no significant difference between two groups indicating that transcatheter and surgical closure had led to equivalent value of electrical remodeling.

In CMR study, we measured RA maximal volume and right ventricle end diastolic volume (RVEDV), RA maximal volume decreased significantly as compared to the base line values post closure in both groups (P value $<0.001$ ). The reduction in RA max volume was more in the transcatheter closure group; however, this difference was not statistically significant when compared with the surgical arm $(P$ value $=0.5)$. RVEDV decreased significantly in both groups as compared to the baseline values $(P$ value $<0.001)$. Transcatheter closure resulted in more significant reduction in the RVEDV than the surgical closure $(P$ value $=0.03)$.
\end{abstract}

\footnotetext{
*Correspondence: nohagamal86@gmail.com

${ }^{2}$ Cardiology Department, Faculty of Medicine, Assiut University, Assiut, Egypt

Full list of author information is available at the end of the article
}

\section{Springer Open}

(๑) The Author(s). 2021 Open Access This article is licensed under a Creative Commons Attribution 4.0 International License, which permits use, sharing, adaptation, distribution and reproduction in any medium or format, as long as you give appropriate credit to the original author(s) and the source, provide a link to the Creative Commons licence, and indicate if changes were made. The images or other third party material in this article are included in the article's Creative Commons licence, unless indicated otherwise in a credit line to the material. If material is not included in the article's Creative Commons licence and your intended use is not permitted by statutory regulation or exceeds the permitted use, you will need to obtain permission directly from the copyright holder. To view a copy of this licence, visit http://creativecommons.org/licenses/by/4.0/. 
Conclusion: Our study showed early significant electromechanical reverse remodeling in most of the study parameters from the baseline values after ASD closure. We found no significant differences in all of the electrical and RA mechanical remodeling parameters with significantly better mechanical remodeling of RV in the device group.

Keywords: Transcatheter ASD closure, Surgical ASD closure, Electrical remodeling, Mechanical remodeling, Cardiac MRI

\section{Background}

ASD is among the most common acyanotic congenital cardiac lesion [1]. Secundum ASD contributes to RA and RV volume overload, and chronic volume overload leads to right sided heart failure, pulmonary hypertension, and atrial arrythmias [2]. ASD closure is assumed to reverse RA and RV changes leading to electrical and mechanical remodeling. Although surgical closure of an ASD is a frequently offered low-risk procedure, it is associated with some morbidities including post pericardiotomy syndrome, arrhythmia, and scar formation [3]. Transcatheter closure of ASD has become an effective alternative to secundum ASD closure, avoiding complications of surgical closure [4]. We used CMR for assessment and evaluation of the RV and RA volumes as it is now considered the gold standard tool [5].

Aim We thought to study RA and RV changes by CMR 3 months after transcatheter and surgical closure and their comparison with electrical remodeling by ECG.

\section{Methods}

This study which is longitudinal observation study was approved by our institutional and local review board, and written informed consent was obtained from all of the patients enrolled in this study. Thirty consecutive patients were included with isolated secundum ASD, 15 patients underwent successful transcatheter ASD device closure and 15 had surgical closure. All patients were subjected to full history, proper physical examination, 12 leads ECG and CMR before the ASD closure, and 3 months later.

Patients with secundum ASD and left to right shunt, sinus rhythm with increased RV volume load (QP/QS ratio > 1.5 and/or RV dilation) were included. Patients with secundum ASD and associated coronary artery disease or other congenital heart disease were excluded. Patients with pulmonary arterial hypertension and pulmonary vascular resistance (PVR) $>5$ woods units (this according to the ESC guidelines of GUCH 2010 which considered ASD closure if PVR $\geq 5$ as class IIB indication for closure which was also stated in the ESC guidelines 2020 as class III in PVR $>5$ despite targeted $\mathrm{PAH}$ treatment) and partial anomalous pulmonary venous return were also excluded.

All patients were presented in the joint cardio-surgical meeting with the cardiology and cardiothoracic surgery. Patients with evidence of elevated pulmonary artery pressure or patients for whom non-invasive assessment of the pulmonary artery pressure was impossible or inconclusive underwent an invasive haemodynamic study as well as assessment of the pulmonary artery pressure and pulmonary vascular resistance. So, not all the surgical study cohorts underwent invasive pulmonary artery pressure evaluation. All patients who underwent transcatheter closure had assessment of the pulmonary vascular resistance.

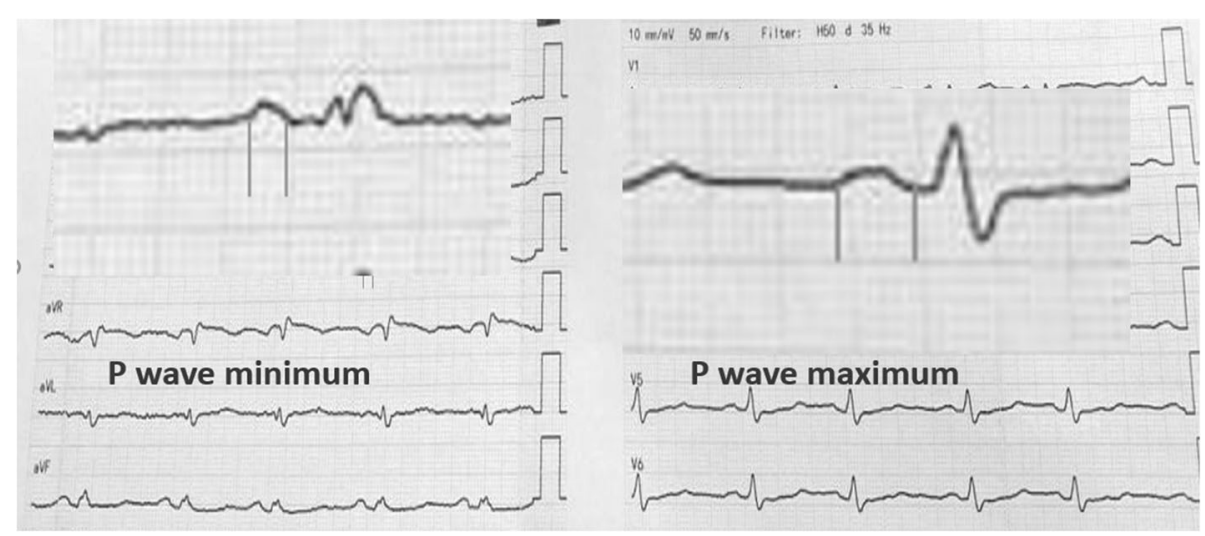

Fig. 112 leads ECG in patient with secundum ASD showed P wave duration (Pmax, P min) measurement 


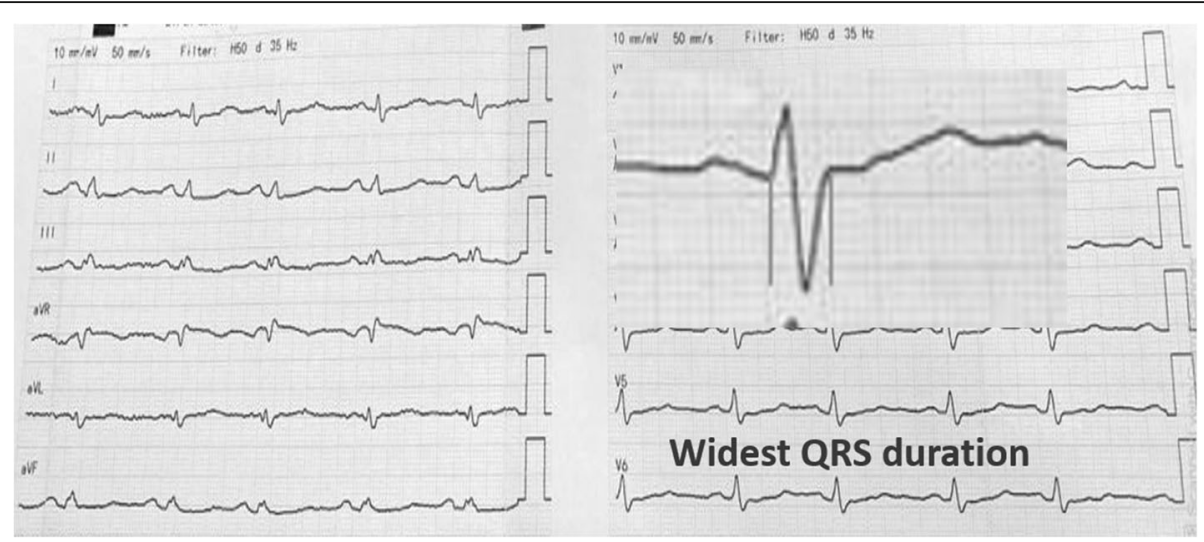

Fig. 212 leads ECG in patient with secundum ASD showed QRS duration measurement

A custom-made sheet was made for all the patients, 12 leads surface ECG as well as CMR assessment were obtained preclosure and 3 months after closure of the ASD.

\section{Electrocardiographic study}

ECG machine used was electrocardiograph ECG-2250Nihon Kohden.

A 12-leads ECG was recorded at a speed of $50 \mathrm{~mm} / \mathrm{s}$ and an amplitude of $1 \mathrm{mV} / \mathrm{cm}$ before and 3 months after ASD closure for evaluation of the following electrical parameters:

$\mathrm{P}$ wave duration is defined as the distance between the junction of baseline with the point of the earliest and point of latest $\mathrm{P}$ wave activity. The longest $\mathrm{P}$ wave duration was noted as $\mathrm{P}$ wave maximum $(\mathrm{P} \max )$ and the shortest duration as $\mathrm{P}$ wave minimum $(\mathrm{P} \min )$ in any of the 12 ECG leads (Fig. 1) [6].

$\mathrm{P}$ wave dispersion $(\mathrm{Pd})$ is defined as the difference between the maximum and the minimum $\mathrm{P}$-wave duration recorded [6]. We selected $P$ wave duration and $P$ wave dispersion as they are strong surrogates for prediction of atrial arrythmia.
QRS duration is defined as the widest QRS complex duration in any lead as measured from the first deflection to the last deflection crossing the isoelectric line (Fig. 2) [7].

QTc interval is defined as the interval between the beginning of the QRS complex and the end of the $\mathrm{T}$ wave and corrected for patients' heart rate using Bazett formula (Fig. 3) [8].

QT dispersion (QTD) is defined as the difference between the longest (QTc max) and the shortest (QTc min) QTc intervals within a 12-leads ECG [8].

\section{Echocardiography either transthoracic (TTE) or transoesophageal (TEE)}

TTE was used to asses mean pulmonary artery pressure (MPAP) from the peak PR Doppler signal using the following formula: MPAP $=4(\text { PR peak velocity })^{2}+$ RAP [9]. TEE was used to assess ASD size and its rims, and exclude anomalous pulmonary venous drainage.

\section{Cardiac magnetic resonance assessment}

All CMR studies were performed with subjects in the supine head first position. Using a 1.5 Tesla MRI scanner

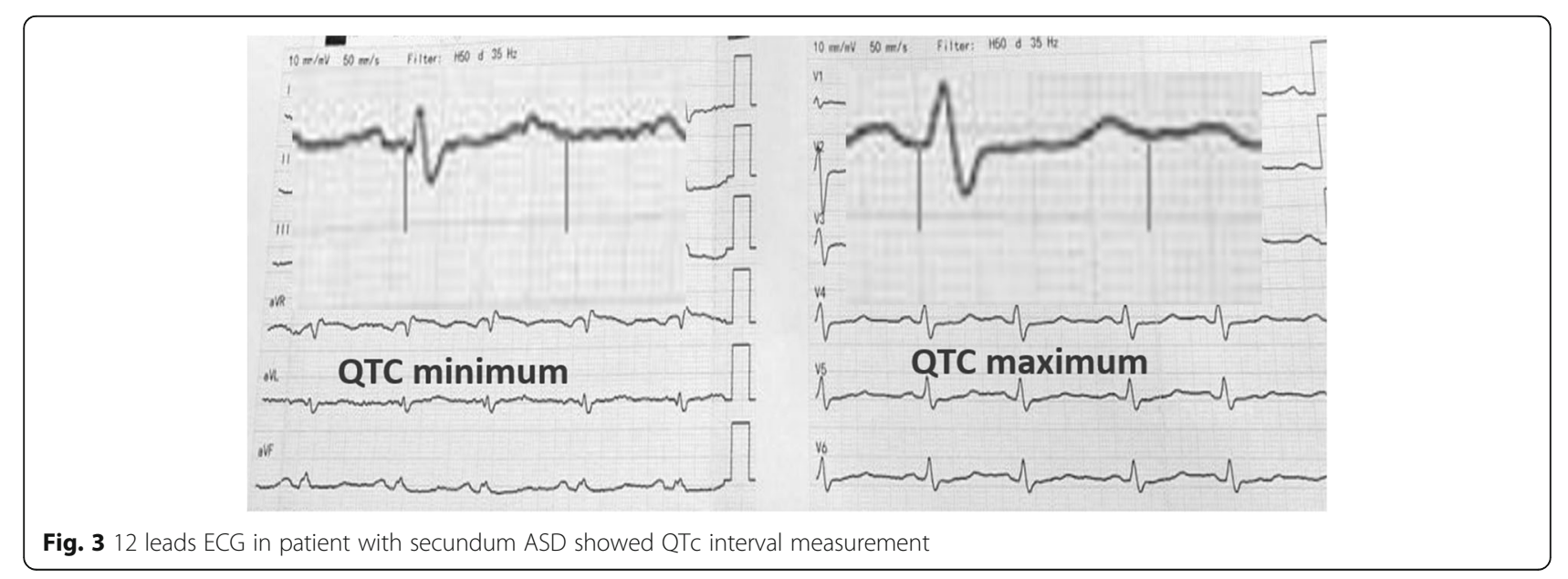


Table 1 Demographic date of studied patients

\begin{tabular}{llll}
\hline & Group $\mathbf{1}$ (device closure) $(\mathbf{n}=\mathbf{1 5})$ & Group 2 (surgical closure) $(\mathbf{n}=\mathbf{1 5})$ & $\boldsymbol{P}$ value \\
\hline Age (years) & $33.73 \pm 13.06$ & $35.33 \pm 15.18$ & 0.75 \\
Sex & & & 0.65 \\
$\quad$ Female & $10(66.7 \%)$ & $10(66.7 \%)$ & $5(33.3 \%)$ \\
$\quad$ Male & $5(33.3 \%)$ & $24.44 \pm 4.02$ & 0.79 \\
BMl $\left(\mathrm{kg} / \mathrm{m}^{2}\right)$ & $24.78 \pm 2.94$ & $93 \pm 9.59$ & 0.78 \\
Heart rate $(\mathrm{bpm})$ & $92 \pm 10.14$ &
\end{tabular}

Data expressed as frequency (percentage), mean (SD). $P$ value was significant if $<0.05$

(Ingenia Philips) using a surface cardiac coil and cardiac imaging software. Scanning was performed with ECG gating during end-expiratory breath-holding phase. Steady-State Precession (SSFP) ECG gated sequences were obtained retrospectively (Image matrix $256 \times 150$, field of view $380 \mathrm{~mm}$, repetition time $52.05 \mathrm{~ms}$, echo time $1.74 \mathrm{~ms}$, and flip angle $70^{\circ}$ ) [10].

MRI was used to assess ASD size, rims and shunt fraction $(\mathrm{QP} \backslash \mathrm{QS})$. For the ventricular image set, the stack of cine SSFP images were acquired in the short axis view from the level of the mitral valve to the left ventricular apex with 8 to 12 slice thickness, and measurements were indexed to the patient's body surface area (BSA) [11]. Analysis of the RV was performed on per slice basis by manual contouring of the endocardial and epicardial borders. Volumes were calculated based on the Simpson's method [12]. We included the trabeculations and papillary muscles as part of the RV volume [13]

RA maximum volume was measured using the biplane area method technique in 4 and 2 chamber views [14]. The maximal RA volume was traced during ventricular systole and was defined as last cine image before opening of the tricuspid valve [14]. The RA appendage was included in the RA volume while the inferior and superior vena cava were excluded [14].

\section{ASD closure}

Percutaneous transcatheter ASD closure was performed when the anatomical characteristics and rims were adequate under general anesthesia with fluoroscopic and TEE guidance. Heparin (100 IU/kg) was given in every case. To avoid over sizing, a 24- or 34-mm sizing balloon (AGA Medical Corp.) was used to measure the diameter of the defect, and the stop-flow method balloon sizing was done with stop flow echo technique and fluoroscopic measurement was used for measurement in every patient. We did two cases through LUPV deployment technique and one through RUPV deployment technique. Balloon-assisted method (BAT) was done in one patient with absent aortic rim and with the help of a contralateral venous sheath.

The procedure was done using Amplatzer septal occluder (ASO) device, its sizes were $24 \pm 6.6 \mathrm{~mm}$ ranging from 11 to $38 \mathrm{~mm}$.

Surgical closure was done for patients with defects that were not suitable for transcatheter closure (with inadequate rims) by means of patch technique.

\section{Statistical analysis}

Data was collected and analysed using SPSS (Statistical Package for Social Science, version 25, IBM, and Armonk, NY). Numerical data was expressed in the form

Table 2 ECG parameters before and after ASD closure in device and surgical group

\begin{tabular}{|c|c|c|c|c|c|c|}
\hline & \multicolumn{2}{|c|}{ Group 1 (device closure) } & \multirow[b]{2}{*}{$P$ value } & \multicolumn{2}{|c|}{ Group 2 (surgical closure) } & \multirow[b]{2}{*}{$P$ value } \\
\hline & Before & After & & Before & After & \\
\hline $\mathrm{HR}$ (bpm) & $92 \pm 10.14$ & $78 \pm 6.76$ & $<0.001$ & $93 \pm 9.59$ & $78.67 \pm 11.87$ & $<0.001$ \\
\hline$P \max (\mathrm{ms})$ & $97.33 \pm 16.67$ & $76 \pm 15.49$ & $<0.001$ & $97.33 \pm 12.79$ & $73.33 \pm 16.32$ & $<0.001$ \\
\hline$P \min (m s)$ & $68 \pm 16.56$ & $48.67 \pm 12.45$ & $<0.001$ & $66.67 \pm 12.34$ & $45.33 \pm 11.87$ & $<0.001$ \\
\hline $\mathrm{Pd}(\mathrm{ms})$ & $29.33 \pm 10.32$ & $27.33 \pm 9.61$ & 0.42 & $32 \pm 12.64$ & $28 \pm 10.14$ & 0.08 \\
\hline QRS (ms) & $104 \pm 18.82$ & $80 \pm 18.51$ & $<0.001$ & $106.67 \pm 14.47$ & $86.67 \pm 17.99$ & $<0.001$ \\
\hline QTc max(ms) & $478.53 \pm 36.79$ & $412.53 \pm 38.03$ & $<0.001$ & $470.53 \pm 65.70$ & $405.93 \pm 63.08$ & $<0.001$ \\
\hline QTD (ms) & $70.33 \pm 24.04$ & $60.26 \pm 28.56$ & 0.003 & $80.73 \pm 30.38$ & $60.27 \pm 28.57$ & 0.001 \\
\hline
\end{tabular}

$P$ max $P$ wave maximum, $P$ min $P$ wave minimum, $P d P$ wave dispersion, $Q T D$ QTdispersion. Data expressed as frequency (percentage), mean (SD). $P$ value was significant if $<0.05$ 
Table 3 ECG parameters comparing both groups

\begin{tabular}{|c|c|c|c|}
\hline & $\begin{array}{l}\text { Group } 1 \text { (device closure) } \\
(n=15)\end{array}$ & $\begin{array}{l}\text { Group } 2 \text { (surgical closure) } \\
(n=15)\end{array}$ & $P$ value \\
\hline \multicolumn{4}{|l|}{ Heart rate (bpm) } \\
\hline Baseline & $92 \pm 10.14$ & $93 \pm 9.59$ & 0.78 \\
\hline Post closure & $78 \pm 6.76$ & $78.67 \pm 11.87$ & 0.85 \\
\hline Percentage of change & $(-) 14.68 \pm 8.07$ & (-) $15.40 \pm 8.89$ & 0.81 \\
\hline \multicolumn{4}{|l|}{ P wave maximum (ms) } \\
\hline Baseline & $97.33 \pm 16.67$ & $97.33 \pm 12.79$ & 0.99 \\
\hline Post closure & $76 \pm 15.49$ & $73.33 \pm 16.32$ & 0.65 \\
\hline Percentage of change & $(-) 21.67 \pm 9.51$ & $(-) 24.88 \pm 10.41$ & 0.38 \\
\hline \multicolumn{4}{|l|}{$P$ wave minimum (ms) } \\
\hline Baseline & $68 \pm 16.56$ & $66.67 \pm 12.34$ & 0.80 \\
\hline Post closure & $48.67 \pm 12.45$ & $45.33 \pm 11.87$ & 0.45 \\
\hline Percentage of change & $(-) 27.89 \pm 9.90$ & (-) $31.11 \pm 14.93$ & 0.49 \\
\hline \multicolumn{4}{|l|}{ P wave dispersion (ms) } \\
\hline Baseline & $29.33 \pm 10.32$ & $32 \pm 12.64$ & 0.53 \\
\hline Post closure & $27.33 \pm 9.61$ & $28 \pm 10.14$ & 0.85 \\
\hline Percentage of change & $(-) 3.67 \pm 0.36$ & $(-) 8.88 \pm 3.78$ & 0.47 \\
\hline \multicolumn{4}{|l|}{ QRS complex (ms) } \\
\hline Baseline & $104 \pm 18.82$ & $106.67 \pm 14.47$ & 0.66 \\
\hline Post closure & $80 \pm 18.51$ & $86.67 \pm 17.99$ & 0.32 \\
\hline Percentage of change & (-) $22.84 \pm 11.64$ & (-) $19.11 \pm 10.25$ & 0.36 \\
\hline \multicolumn{4}{|l|}{ QT maximum (ms) } \\
\hline Baseline & $478.53 \pm 36.79$ & $470.53 \pm 65.70$ & 0.68 \\
\hline Post closure & $412.53 \pm 38.03$ & $405.93 \pm 63.08$ & 0.73 \\
\hline Percentage of change & $(-) 13.63 \pm 6.98$ & $(-) 13.67 \pm 6.98$ & 0.98 \\
\hline \multicolumn{4}{|l|}{ QT minimum (ms) } \\
\hline Baseline & $405.73 \pm 41.27$ & $389.80 \pm 63.74$ & 0.42 \\
\hline Post closure & $345.53 \pm 71.84$ & $345.67 \pm 56.40$ & 0.99 \\
\hline Percentage of change & (-) $14.99 \pm 5.88$ & $(-) 11.11 \pm 6.29$ & 0.38 \\
\hline \multicolumn{4}{|l|}{ QT dispersion (ms) } \\
\hline Baseline & $70.33 \pm 24.04$ & $80.73 \pm 30.38$ & 0.30 \\
\hline Post closure & $60.26 \pm 28.56$ & $60.27 \pm 28.57$ & 0.66 \\
\hline Percentage of change & (-) $19.33 \pm 11.28$ & (-) $24.98 \pm 10.16$ & 0.42 \\
\hline
\end{tabular}

$P$ max $P$ wave maximum, $P$ min $P$ wave minimum, $P d P$ wave dispersion, $Q T D$ QTdispersion. Data expressed as frequency (percentage), mean (SD). $P$ value was significant if $<0.05$

of mean $\pm \mathrm{SD}$, while categorical data was expressed in the form of frequency and percentage.

Categorical data of different groups was compared by chi-square test while numerical data of both groups was compared by Mann-Whitney U test. Baseline and follow up data of the same group was compared by Wilcoxon signed-rank test. Percentage of change between baseline and follow-up data was calculated by the following equation; percentage of change $=(($ follow up-baseline data $) /$ baseline data)) $\times 100$.
Level of confidence was kept at $95 \%$ and hence, $P$ value was considered to be significant if $<0.05$.

\section{Results}

Demographic and clinical data of the study groups

The mean age of patients who underwent device closure was $33.73 \pm 13.06$ years while the mean age of those who underwent surgical closure was $35.33 \pm 15.18$ years with insignificant difference between both groups $(P=$ 0.75 ) (Table 1). In both groups, majority (66.7\%) of 


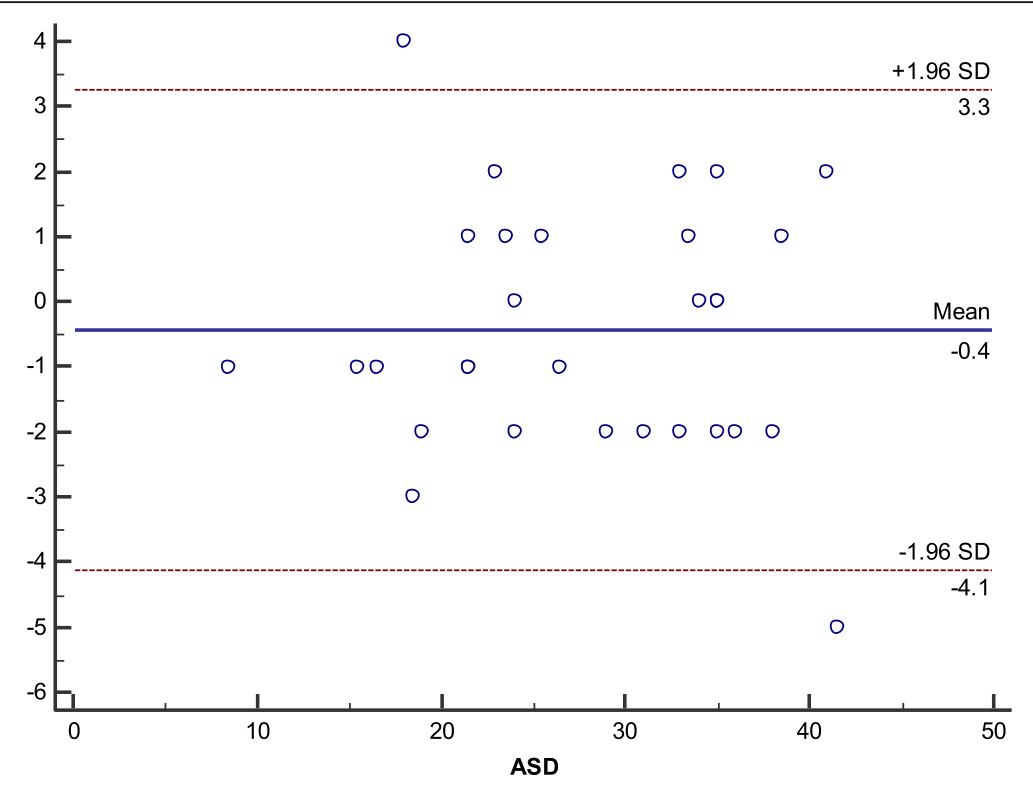

Fig. 4 Bland-Altman plot comparing ASD with TEE and MRI showed strong degree of agreement (0.96)

patients were females and less than 40 years old. There were insignificant differences between both groups as regards $\mathrm{HR}$ and BMI. All patients were neither DM nor HTN.

\section{Assessment of the electrical remodeling parameters}

Both groups showed significant reduction in all ECG parameters-apart from $\mathrm{P}$ wave dispersion-after ASD closure when compared to the baseline values (Table 2). However, when we compared between the two methods of closure, we did not find significant difference between them as regards the electrical parameters (Table 3).

ASD diameter, rims assessment, MPAP, and Shunt fraction (QP/QS)

Assessment of ASD diameter and rims using TEE and MRI showed strong degree of agreement (0.96), using Bland-Altman plot as illustrated in Fig. 4.

Shunt fraction assessed by CMR showed insignificant statistical difference between both groups (Table 5).

Patients underwent device closure had significantly lower MPAP $(18.13 \pm 7.21$ vs. $23.93 \pm 6.63$ (mmHg);
$P=0.03)$ in comparison to surgical device after closure with statistically insignificant difference preclosure (Tables 4 and 5).

\section{Assessment of the mechanical remodeling by CMR $R A$ measurements}

RA maximal volume was significantly reduced in both groups when compared with the baseline values (Table 6). However, there was no significant difference between both groups (Table 7).

\section{$R V$ measurements}

RVEDV showed significant changes from the baseline measurements in both groups after ASD closure (Table 6). Comparing between both groups showed significant difference between them with more reduction in the transcatheter arm (Table 7).

\section{Discussion}

We included a total number of thirty adult patients in a prospective study to compare short term electrical and mechanical remodeling parameters after transcatheter

Table 4 PAP in device and surgical group

\begin{tabular}{|c|c|c|c|c|c|c|}
\hline & \multicolumn{2}{|c|}{$\begin{array}{l}\text { Group } 1 \text { (device closure) } \\
(n=15)\end{array}$} & \multirow[b]{2}{*}{$P$ value } & \multicolumn{2}{|c|}{$\begin{array}{l}\text { Group } 2 \text { (surgical closure) } \\
(n=15)\end{array}$} & \multirow[b]{2}{*}{$P$ value } \\
\hline & Before closure & After closure & & Before closure & After closure & \\
\hline MPAP (mmHg) & $27.93 \pm 5.18$ & $18.13 \pm 7.21$ & 0.001 & $30.67 \pm 5.30$ & $23.93 \pm 6.63$ & 0.001 \\
\hline
\end{tabular}

Data expressed as frequency (percentage), mean (SD). $P$ value was significant if $<0.05$ 
Table 5 PAP and shunt fraction (QP/QS) in both groups

\begin{tabular}{llll}
\hline & $\begin{array}{l}\text { Device closure } \\
(\boldsymbol{n}=\mathbf{1 5})\end{array}$ & $\begin{array}{l}\text { Surgical closure } \\
(\boldsymbol{n}=\mathbf{1 5})\end{array}$ & $\boldsymbol{P}$ value \\
\hline MPAP $(\mathrm{mmHg})$ & & & \\
Baseline & $27.93 \pm 5.18$ & $30.67 \pm 5.30$ & 0.16 \\
Post-closure & $18.13 \pm 7.21$ & $23.93 \pm 6.63$ & 0.03 \\
QP/QS ratio & & & \\
Before closure & $2.03 \pm 0.25$ & $2.23 \pm 0.40$ & 0.11 \\
After closure & $0.95 \pm 0.13$ & $1.04 \pm 0.09$ & 0.04 \\
\hline
\end{tabular}

Data expressed as frequency (percentage), mean (SD). $P$ value was significant if $<0.05$

$P A P$ pulmonary artery pressure, $Q P I Q S$ shunt fraction

and surgical ASD closure. Each group contained 15 age-, sex-, and BSA-matched patients.

The main purpose of ASD closure is the elimination of shunt with excess right heart volume. In our cohort, ASD surgical closure resulted in both electrical and mechanical remodeling of the same as percutaneous closure with better RV remodeling results in the device group. In early series, RV enlargement persisted in almost two thirds of both pediatric and adult patients over a mid-term echocardiography follow-up [15].

CMR has been shown to be both reliable and reproducible in terms of quantitative RV assessment. The combination of a time-resolved 3D data set, clear distinction between the blood pool and the myocardium, and high spatial and temporal resolutions allow for accurate measurements of the RV, regardless of its morphology or orientation within the thorax, and without geometric assumptions [16].

\section{Atrial electrical remodeling}

In our cohort, there was a reduction in the electrical parameters-resting heart rate, $\mathrm{Pd}, \max$, and $\min \mathrm{P}$ wave duration after ASD closure in comparison to the baseline measurements in both groups, all showed statistically significant $\mathrm{P}$ value $<0.05$, with exception of $\mathrm{Pd}$ which was statistically insignificant with $\mathrm{P}$ value $=0.4$ in group 1 and 0.08 in group 2 . Our results agreed with the study conducted by Kamphuis et al. [7], who found that the reduction in the resting heart rate after ASD closure was due to decrease in RA size, and this led to deactivation of the Bainbridge reflex [17] and decrease stretching of the pacemaker tissue in the sinus node [18].

The change of electrical remodeling parametersPmax, $\mathrm{P}$ min, and $\mathrm{Pd}-$ from the baseline measurements after ASD closure was more in the surgical group than in the transcatheter group; however, the difference between the two groups did not reach a statistical significance $P$ value $>0.05$. This indicates that transcatheter and surgical ASD closure had led to equivalent degrees of electrical remodeling with no superiority over each other. This partially agree with the results of the two studies conducted by Baspinar et al. [19] and Muzaffer et al. [20], who reported no difference in the $\mathrm{P}$ max values measured early after transcatheter and surgical ASD closure. In contrary to our study, they demonstrated significant reduction in the $\mathrm{Pd}$ measurements in the surgical arm in comparison to the transcatheter arm. This effect was clarified by the bulk of the device. Also, Paç et al. [6] found in their study that the atrial disc diameter and device sizes were the strongest correlates with the change in the Pd values. The discrepancy between our findings and the studies described above may be explained by the difference in the mean age of the research cohorts. The $\mathrm{Pac}$ et al. study included younger patients (mean age $=7.2 \pm 3.3$ ), and the mean age of our cohort was $=34.53 \pm 14.12$. This observation may emphasize the importance of the duration of shunt as an important factor affecting the degree of electrical remodeling, where longer duration of shunt may result in less early reversibility of $\mathrm{Pd}$ values with resultant prolongation of atrial refractoriness heterogenicity.

\section{Ventricular electrical remodeling}

In our study, there was significant shortening in the QRS complex duration, QTc max, and QTD after ASD closure as compared to the baseline measurements in both groups. However, there was no significant difference between the two groups. This agree with Veldtman et al. [21] and Gatzoulis et al. [22], who showed significant reduction in the QRS complex duration after ASD device closure; this was explained by the reduction of RV volume overload,

Table 6 Parameters of RA and RV in device and surgical groups

\begin{tabular}{|c|c|c|c|c|c|c|}
\hline & \multicolumn{2}{|c|}{$\begin{array}{l}\text { Group } 1 \text { (device closure) } \\
(n=15)\end{array}$} & \multirow[b]{2}{*}{$P$ value } & \multicolumn{2}{|c|}{$\begin{array}{l}\text { Group } 2 \text { (surgical closure) } \\
(n=15)\end{array}$} & \multirow[b]{2}{*}{$P$ value } \\
\hline & Before closure & After closure & & Before closure & After closure & \\
\hline RA maximal volume $(\mathrm{mm})$ & $74.53 \pm 23.98$ & $46.88 \pm 12.77$ & $<0.001$ & $81.90 \pm 30.07$ & $55.38 \pm 18.03$ & $<0.001$ \\
\hline RVEDV (mm) & $133.33 \pm 25.26$ & $87.10 \pm 14.08$ & $<0.001$ & $152.33 \pm 52.36$ & $106.60 \pm 31.21$ & $<0.001$ \\
\hline
\end{tabular}

RA: right atrium, RVEDV: right ventricle end diastolic volume. Data expressed as frequency (percentage), mean (SD). $P$ value was significant if $<0.05$ 
Table 7 Parameters of RA and RV in comparison among two groups

\begin{tabular}{llll}
\hline & $\begin{array}{l}\text { Group 1 (device closure) } \\
(\boldsymbol{n}=\mathbf{1 5})\end{array}$ & $\begin{array}{l}\text { Group 2 (surgical closure) } \\
(\boldsymbol{n}=\mathbf{1 5})\end{array}$ & $\begin{array}{c}\boldsymbol{P} \text { value } \\
\text { RA maximum volume }\left(\mathrm{ml} / \mathrm{mm}^{2}\right)\end{array}$ \\
$\quad$ & $74.53 \pm 23.98$ & $81.90 \pm 30.07$ & 0.46 \\
$\quad$ Before closure & $46.88 \pm 12.77$ & $55.38 \pm 18.03$ & 0.14 \\
After closure & $(-) 34.38 \pm 17.47$ & $(-) 30.15 \pm 17.11$ & 0.50 \\
Percentage of change & & & 0.21 \\
RV-EDV $\left(\mathrm{ml} / \mathrm{mm}^{2}\right)$ & $133.33 \pm 25.26$ & $152.33 \pm 52.36$ & 0.03 \\
Before closure & $87.10 \pm 14.08$ & $106.60 \pm 31.21$ & $(-) 27.20 \pm 15.07$ \\
After closure & $(-) 32.60 \pm 13.55$ & 0.31 \\
Percentage of change &
\end{tabular}

$R A$ right atrium, RVEDV right ventricle end diastolic volume. Data expressed as frequency (percentage), mean (SD). $P$ value was significant if $<0.05$

geometrical remodeling, and improvement of pulmonary artery pressure with partial reversal of right bundle branch block. Also, Rücklová et al. [23] found significant reduction in the QT dispersion 1 month after the intervention either transcatheter or surgical closure. We did not find superiorly of any method of closure on the ventricular electrical remodeling.

\section{Mechanical remodeling by CMR \\ Atrial measurements}

Our study showed significant reduction in the indexed RA maximal volume and indexed RVEDV after ASD closure in both groups as compared to baseline measurements (Figs. 5 and 6). There was tendency towards more reverse remodeling in the indexed RA maximal volume in the device group; however, this was not statistically significant when compared to the surgical group.

\section{Ventricular remodeling}

Transcatheter ASD closure had led to more reverse remodeling in the indexed RVEDV measurements when compared to the surgical arm (Fig. 5). This agreed with Pascotto et al. [24] who reported failure of the surgical ASD closure to completely revert the right ventricular chamber overload, they explained this by either functional changes secondary to the effects of the cardiopulmonary bypass technique or cardiac geometric alteration resulting from opening of the pericardial sac. Our results disagree with the study performed by Foo et al. [25] who found no difference between the surgical and device closure groups. This can be explained by the difference of modalities used for analysis of the RV volumes. In our study, we used the CMR which is considered as the gold standard for RV volumetric assessment, while Foo et al. used (2D) echocardiography which relies heavily on geometrical assumption.

\section{Limitations and recommendations}

- Our study population was relatively small in number with short to intermediate term follow-up. Larger sample size and longer-term follow-up are needed to correlate this finding with clinical outcome and incidence of arrhythmia.
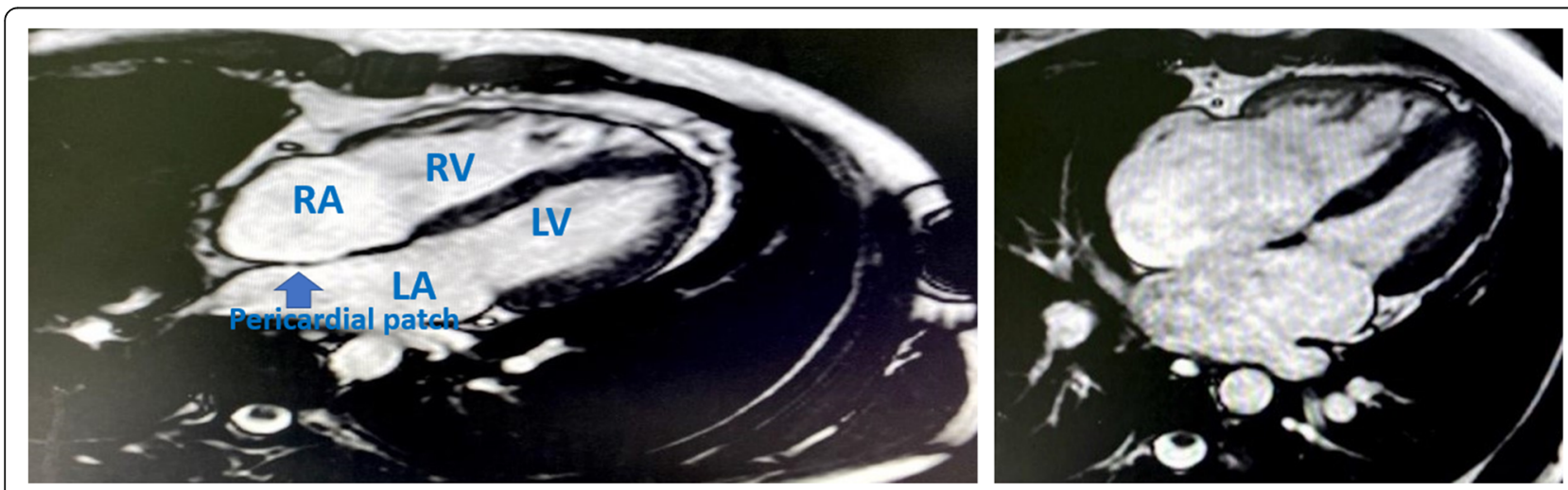

Fig. 5 Cine SSFP 4 chamber MRI view in surgically closed case by conventional method with revolution of RA and RV volumes 

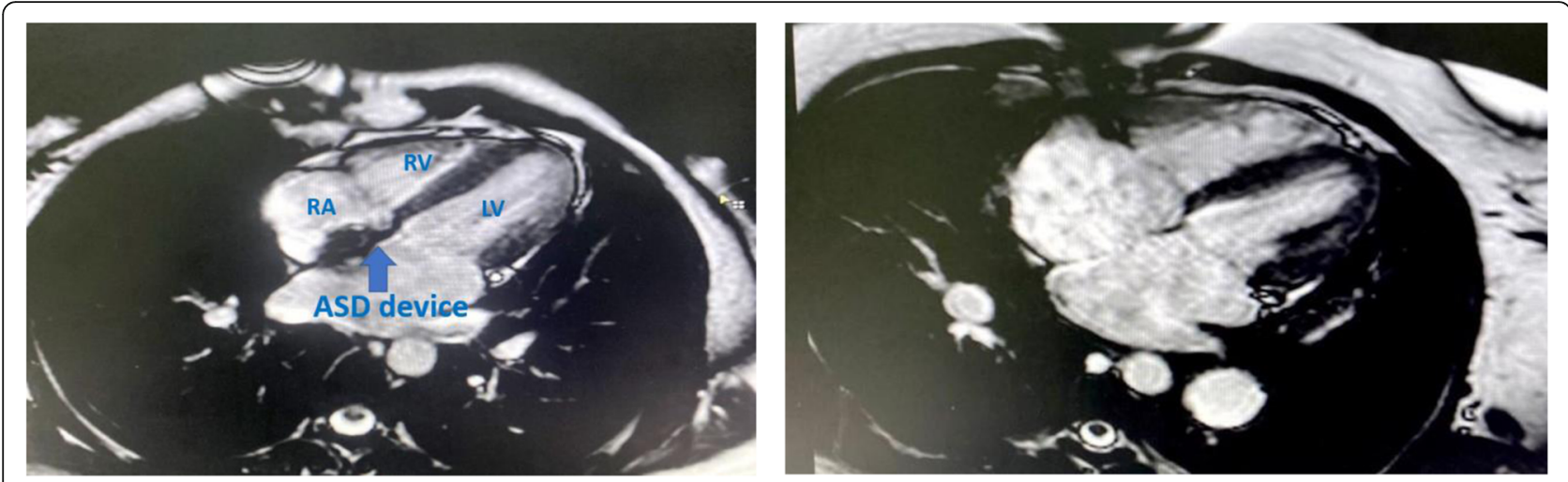

Fig. 6 Cine SSFP 4 chamber MRI view in transcatheter closed case by ASO

\section{Conclusion}

- Transcatheter and surgical ASD closure have led to equivalent degrees of atrial and ventricular electrical remodeling, atrial mechanical remodeling, and better ventricular mechanical remodeling as evidenced by CMR.

- Pd values did not change significantly from the baseline despite significant mechanical changes after both methods of ASD closure.

- Transcatheter ASD closure had led to better RV mechanical remodeling than surgical closure.

\section{Abbreviations}

ASD: Atrial septal defect; ECG: Electrocardiogram; CMR: Cardiac magnetic resonance; Pd: P wave dispersion; RA: Right atrium; RVEDV: Right ventricle end diastolic volume; PAH: Pulmonary arterial hypertension; PVR: Pulmonary vascular resistance; BSA: Body surface area; TEE: Transoesophageal echocardiography; $\mathrm{P}$ max: $\mathrm{P}$ wave maximum; $\mathrm{P}$ min: $\mathrm{P}$ wave minimum; $\mathrm{Pd}$ : $\mathrm{P}$ wave dispersion; QTD: QT dispersion; SSFP: Steady-state precession; TTE: Transthoracic echocardiography; ASO: Amplatzer septal occluder

\section{Acknowledgements}

Not applicable

\section{Authors' contributions}

AM has contributed in the conceptualization, methodology, data curation, software, validation, formal analysis, investigation, resource, writing-original draft, writing-review and editing, visualization, supervision, and project administration. NMG took part in conceptualization, methodology, data curation, software, validation, formal analysis, investigation, resource, writing_original draft, writing - review and editing, visualization, supervision, and project administration. ANM took part in methodology, data curation, software, validation, formal analysis, investigation, resource, visualization, supervision, and project administration. SRD took part in methodology, data curation, software, validation, formal analysis, investigation, resource, writing-original draft, and writing-project administration. SEH took part in methodology, data curation, software, validation, formal analysis, investigation, resource, writing —original draft, and writing - project administration. KME took part in conceptualization, methodology, data curation, software, validation, formal analysis, investigation, resource, visualization, supervision, and project administration. All authors have read and approved the final manuscript.

\section{Funding}

None. This research did not receive any specific grant from funding agencies in the public, commercial, or not-for-profit sectors.
Availability of data and materials

The datasets used and/or analyzed during the current study are available from the corresponding author on reasonable request.

\section{Declarations}

Ethics approval and consent to participate

This study was approved by the ethics committee of Assiut University, Institutional Review Board (IRB), (independent ethics committee) (IEC); Project Approval Number: CA54 19-9635 55. An informed written consent was obtained from all of the patients enrolled in this study. The study has been carried out in accordance with The Code of Ethics of the World Medical Association (Declaration of Helsinki).

Consent for publication

Not applicable

\section{Competing interests}

All the authors declare that they have no competing interests.

\section{Author details}

${ }^{1}$ Cardiology Department, Congenital and Structural Heart Disease Unit, Faculty of Medicine, Ain Shams University Hospitals, Cairo, Egypt. ${ }^{2}$ Cardiology Department, Faculty of Medicine, Assiut University, Assiut, Egypt.

${ }^{3}$ Cardiothoracic Surgery Department, Faculty of Medicine, Assiut University, Assiut, Egypt.

Received: 6 October 2020 Accepted: 26 May 2021

Published online: 10 June 2021

\section{References}

1. Silvestry FE, Cohen MS, Armsby LB, Burkule NJ, Fleishman CE, Hijazi ZM, Lang RM, Rome JJ, Wang Y (2015) Guidelines for the echocardiographic assessment of atrial septal defect and patent foramen ovale: from the American Society of Echocardiography and Society for Cardiac Angiography and Interventions. Journal of the American Society of Echocardiography 28(8):910-958. https://doi.org/10.1016/.echo.2015.05.015

2. Baumgartner H, Bonhoeffer P, De Groot N, De Haan F, Deanfield J, Galie N Gatzoulis M, Gohlke-Baerwolf C, Kaemmerer H, Kilner P, Task Force on the Management of Grown-up Congenital Heart Disease of the European Society of C, Association for European Paediatric C, Guidelines ESCCFP (2010) ESC Guidelines for the management of grown-up congenital heart disease (new version 2010). Eur Heart J 31(23):2915-2957

3. Butera G, Biondi-Zoccai G, Sangiorgi G, Abella R, Giamberti A, Bussadori C, Sheiban I, Saliba Z, Santoro T, Pelissero G (2011) Percutaneous versus surgical closure of secundum atrial septal defects: a systematic review and meta-analysis of currently available clinical evidence. Eurolntervention 7(3): 377-385. https://doi.org/10.4244/EIJV7I3A63

4. Berger F, Ewert P, Boöjrnstad PG, Dähnert I, Krings G, Brilla-Austenat I, Vogel M, Lange PE (1999) Transcatheter closure as standard treatment for most interatrial defects: experience in 200 patients treated with the Amplatzer ${ }^{\mathrm{TM}}$ 
Septal Occluder. Cardiol Young. 9(5):468-473. https://doi.org/10.1017/S104 7951100005369

5. Petersen SE, Aung N, Sanghvi MM, Zemrak F, Fung K, Paiva JM, Francis JM, Khanji MY, Lukaschuk E, Lee AM (2017) Reference ranges for cardiac structure and function using cardiovascular magnetic resonance (CMR) in Caucasians from the UK Biobank population cohort. J Cardiovasc Magn Reson. 19(1):18. https://doi.org/10.1186/s12968-017-0327-9

6. Paç FA, Balli S, Topaloglu S, Ece I, Oflaz MB (2012) Analysis of maximum Pwave duration and dispersion after percutaneous closure of atrial septal defects: comparison of two septal occluders. Anadolu Kardiyol Derg. 12(3): 249-254. https://doi.org/10.5152/akd.2012.069

7. Kamphuis VP, Nassif M, Man S-C, Swenne CA, Kors JA, Vink AS, ten Harkel AD, Maan AC, Mulder BJ, de Winter RJ (2019) Electrical remodeling after percutaneous atrial septal defect closure in pediatric and adult patients. Int J Cardiol. 285:32-39. https://doi.org/10.1016/.ijijard.2019.02.020

8. Guray U, Guray Y, Mecit B, Yilmaz MB, Sasmaz H, Korkmaz S (2004) Maximum $\mathrm{p}$ wave duration and $\mathrm{p}$ wave dispersion in adult patients with secundum atrial septal defect: the impact of surgical repair. Ann Noninvasive Electrocardiol. 9(2):136-141. https://doi.org/10.1111/j.1542-474X.2004.92532.x

9. Parasuraman S, Walker S, Loudon BL, Gollop ND, Wilson AM, Lowery C, Frenneaux MP (2016) Assessment of pulmonary artery pressure by echocardiography a comprehensive review. Int I Cardiol Heart Vasc. 12:45-51

10. Rominger MB, Bachmann GF, Pabst W, Rau WS (1999) Right ventricular volumes and ejection fraction with fast cine MR imaging in breath-hold technique: applicability, normal values from 52 volunteers, and evaluation of 325 adult cardiac patients. Journal of Magnetic Resonance Imaging: J Magn Reson Imaging. 10(6):908-918. https://doi.org/10.1002/(SICI)1522-2586(1 99912)10:6<908::AID-JMRI2>3.0.CO;2-2

11. Alfakih K, Plein S, Thiele H, Jones T, Ridgway JP, Sivananthan MU (2003) Normal human left and right ventricular dimensions for MRI as assessed by turbo gradient echo and steady-state free precession imaging sequences. Journal of Magnetic Resonance Imaging: J Magn Reson Imaging. 17(3):323329. https://doi.org/10.1002/jmri.10262

12. Reiter G, Reiter U, Rienmüller R, Gagarina N, Ryabikin A (2004) On the value of geometry-based models for left ventricular volumetry in magnetic resonance imaging and electron beam tomography: a Bland-Altman analysis. Eur J Radiol. 52(2):110-118. https:/doi.org/10.1016/j.ejrad.2003.10.003

13. Hudsmith LE, Petersen SE, Francis JM, Robson MD, Neubauer S (2005) Normal human left and right ventricular and left atrial dimensions using steady state free precession magnetic resonance imaging. J Cardiovasc Magn Reson. 7(5):775-782. https://doi.org/10.1080/10976640500295516

14. Maceira AM, Cosín-Sales J, Roughton M, Prasad SK, Pennell DJ (2013) Reference right atrial dimensions and volume estimation by steady state free precession cardiovascular magnetic resonance. J Cardiovasc Magn Reson. 15(1):1-10

15. Ning S, Fazal H, Cook D, Wood M, Duncan W, Rowe R (1984) Right ventricular size and ventricular septal motion after repair of atrial septal defect in children. Canadian journal of surgery. Can J Surg 27(4):395

16. Moon JC, Lorenz CH, Francis JM, Smith GC, Pennell DJ (2002) Breath-hold FLASH and FISP cardiovascular MR imaging: left ventricular volume differences and reproducibility. Radiology 223(3):789-797. https://doi.org/1 $0.1148 /$ radiol.2233011181

17. Crystal GJ, Salem MR (2012) The Bainbridge and the "reverse" Bainbridge reflexes: history, physiology, and clinical relevance. Anesth Analg. 114(3): 520-532. https://doi.org/10.1213/ANE.0b013e3182312e21

18. MacDonald EA, Stoyek MR, Rose RA, Quinn TA (2017) Intrinsic regulation of sinoatrial node function and the zebrafish as a model of stretch effects on pacemaking. Prog Biophys Mol Biol. 130(Pt B):198-211. https://doi.org/10.1 016/j.pbiomolbio.2017.07.012

19. Baspinar O, Sucu M, Koruk S, Kervancioglu M, Ustunsoy H, Deniz H, Kilinc M (2011) P-wave dispersion between transcatheter and surgical closure of secundum-type atrial septal defect in childhood. Cardiol Young. 21(1):15-18. https://doi.org/10.1017/S1047951110001307

20. Aslan M, Erturk M, Turen S, Uzun F, Surgit O, Ozbay Ozyilmaz S, Rifat Yildirim M, Faruk Baycan O, Uygur B, Yildirim A (2014) Effects of percutaneous closure of atrial septal defect on left atrial mechanical and conduction functions. Eur Heart J Cardiovasc Imaging. 15(10):1117-1124. https://doi.org/10.1093/ehjic/jeu089

21. Veldtman GR, Razack V, Siu S, El-Hajj H, Walker F, Webb GD, Benson LN, McLaughlin PR (2001) Right ventricular form and function after percutaneous atrial septal defect device closure. J Am Coll Cardiol. 37(8): 2108-2113. https://doi.org/10.1016/S0735-1097(01)01305-5
22. Gatzoulis MA, Redington AN, Somerville J, Shore DF (1996) Should atrial septal defects in adults be closed? Ann Thorac Surg. 61(2):657-659. https:// doi.org/10.1016/0003-4975(95)01043-2

23. Rücklová K, Koubský K, Tomek V, Kubuš P, Janoušek J (2016) Prolonged repolarization in atrial septal defect: An example of mechanoelectrical feedback due to right ventricular volume overload. Heart Rhythm. 13(6): 1303-1308. https://doi.org/10.1016/j.hrthm.2016.01.032

24. Pascotto M, Santoro G, Cerrato F, Caputo S, Bigazzi MC, lacono C, Carrozza M, Russo MG, Caianiello G, Calabrò R (2006) Time-course of cardiac remodeling following transcatheter closure of atrial septal defect. Int J Cardiol. 112(3):348-352. https://doi.org/10.1016/j.jicard.2005.10.008

25. Foo JS, Lazu M, Pang SY, Lee PT, Tan JL (2018) Comparative analysis of right heart chamber remodeling after surgical and device secundum atrial septal defect closure in adults. J Interv Cardiol. 31(5):672-678. https://doi.org/1 $0.1111 /$ joic. 12528

\section{Publisher's Note}

Springer Nature remains neutral with regard to jurisdictional claims in published maps and institutional affiliations.

\section{Submit your manuscript to a SpringerOpen ${ }^{\circ}$ journal and benefit from:}

- Convenient online submission

- Rigorous peer review

- Open access: articles freely available online

- High visibility within the field

- Retaining the copyright to your article

Submit your next manuscript at $\boldsymbol{\nabla}$ springeropen.com 